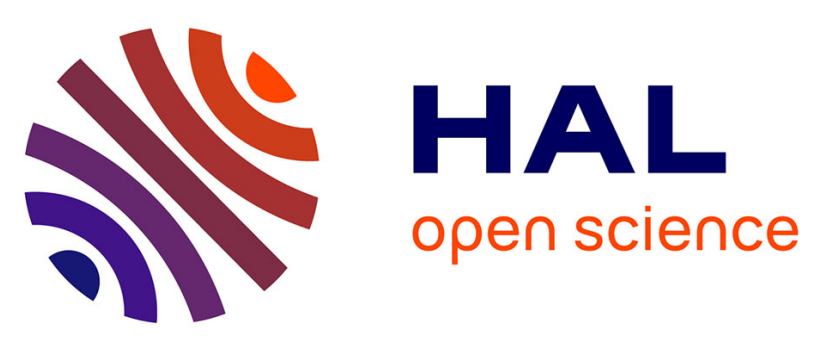

\title{
A Chronometric Comparison of Actual and Imaged Complex Movement Patterns
}

Claire Calmels, Paul Holmes, Lopez Emilie, Véronique Naman

\section{To cite this version:}

Claire Calmels, Paul Holmes, Lopez Emilie, Véronique Naman. A Chronometric Comparison of Actual and Imaged Complex Movement Patterns. Journal of Motor Behavior, 2006, 38 (5), pp.339-348. hal01697417

\section{HAL Id: hal-01697417 https://hal-insep.archives-ouvertes.fr/hal-01697417}

Submitted on 31 Jan 2018

HAL is a multi-disciplinary open access archive for the deposit and dissemination of scientific research documents, whether they are published or not. The documents may come from teaching and research institutions in France or abroad, or from public or private research centers.
L'archive ouverte pluridisciplinaire HAL, est destinée au dépôt et à la diffusion de documents scientifiques de niveau recherche, publiés ou non, émanant des établissements d'enseignement et de recherche français ou étrangers, des laboratoires publics ou privés. 
1 Running head: CHRONOMETRIC COMPARISON 15 21

\section{In Journal of Motor Behavior, in press}

A Chronometric Comparison of Actual and Imaged Complex Movement Patterns

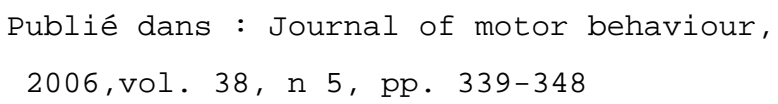

Institut National du Sport et de l’Éducation Physique, Paris, France Paul Holmes
Research Institute for Health and Social Change, Manchester Metropolitan University, UK Emilie Lopez

Institut National du Sport et de l'Éducation Physique, Paris, \& UFRSTAPS Besançon, France Véronique Naman

\author{
Institut National du Sport et de l'Éducation Physique, Paris, France
}

Claire Calmels

$$
\text { Correspondence concerning this article should be addressed to Dr Claire Calmels, }
$$
Département des Sciences du Sport, Institut National du Sport et de l'Education Physique, 11 Avenue du Tremblay, 75012 Paris, France. E.mail: claire.calmels@insep.fr Telephone number: (33-1) 41744577

Fax number: (33-1) 41744535

2 Number of table(s): 3

23 Number of figure(s): 2

4 Date submitted: 10/10/2005

25 First revision submitted: 01/03/2006

26 Second revision submitted: 04/04/2006 


\section{Author Notes}

Claire Calmels, Institut National du Sport et de l'Éducation Physique, Paris, France

Paul Holmes, Research Institute for Health and Social Change, Manchester Metropolitan University, UK

Emilie Lopez, Institut National du Sport et de l'Éducation Physique, Paris, \& UFRSTAPS Besançon, France

Véronique Naman, Institut National du Sport et de l'Éducation Physique, Paris, France

Correspondence concerning this article should be addressed to Dr Claire Calmels, Département des Sciences du Sport, Institut National du Sport et de l'Education Physique, 11 Avenue du Tremblay, 75012 Paris, France. E.mail: claire.calmels@insep.fr Telephone number: (33-1) 41744577

Fax number: (33-1) 41744535

Date submitted: 10/10/2005

First revision submitted: 01/03/2006

Second revision submitted: 04/04/2006 
1 Running head: CHRONOMETRIC COMPARISON

2

3

4

5

6

7

8

9

10

A Chronometric Comparison of Actual and Imaged Complex Movement Patterns 
Abstract

2 The aim of this study was to consider the functional equivalence of internal imagery, external

3 imagery and action execution. Sixteen elite gymnasts imaged and performed a complex

4 gymnastic vault. Ten performers imaged from an internal perspective and six used an external

5 perspective. Whilst the results revealed that the time to image the entire motor task was not

6 significantly different from the time required to physically perform it, irrespective of the

7 imagery perspective employed, the temporal organization of the action was different within

8 the imagery conditions compared to the physical condition. The results do not provide support

9 for the principle of temporal functional equivalence and are discussed in the light of recent

10 findings from the cognitive neuroscience and psychology literature.

Author key-words: principle of functional equivalence, timing paradigm, temporal 
Introduction

The neuroscience and psychophysiology literature has suggested a functional equivalence between action execution, motor imagery and action observation (Crammond, 1997; Decety \& Grèzes, 1999; Grèzes \& Decety, 2001, Grèzes, Fonlupt, \& Decety, 2000; Jeannerod, 1999). The principle of this functional equivalence suggests that similar neural processes are involved in the physical execution, mental simulation and observation of an action, since each operation is proposed to be assigned to the same internal brain representation (Jeannerod, 1994; Jeannerod, 1999).

At a behavioral level, functional equivalence has been considered through timing paradigms by comparing the time taken to physically complete an action with the time required to mentally perform the same task (see Guillot \& Collet, 2005 for a review). A number of studies have shown that motor rules evident for physical actions (e.g., Fitts' Law and The Isochrony Principle) are also maintained during imagery conditions for laboratorybased tasks (Cerritelli, Maruff, Wilson, \& Currie, 2000; Decety \& Jeannerod, 1996; Decety \& Michel, 1989; Maruff et al., 1999).

Durations of mental movements have been shown not to differ significantly from those of physically executed movements for participants. For example, performing a locomotion task with a specific itinerary (Decety, Jeannerod, \& Prablanc, 1989) or an unfamiliar cyclical motor task such as pedalo (Munzert, 2002); executing a graphic gesture (Decety \& Michel, 1989); performing hand/arm movements (Parsons, 1994); completing arm movements in sagittal and horizontal planes under different loading conditions (Papaxanthis, Scieppati, Gentile, \& Pozzo, 2002); and executing whole-body movements after a long exposure to microgravity (Papaxanthis, Pozzo, Kasprinski, Berthoz, 2003) have all been shown to have temporal congruence between actual and imagined movement. However, in some cases, mental and physical durations do differ. The temporal differences have been attributed to 
external factors such as: mass (Cerritelli et al., 2000; Decety et al., 1989); the difficulty of the task (Decety, 1991); biomechanical constraints (Parsons, 1994); and the nature of the skill (Mackay, 1981). Extended time for mental execution of an action has been found in comparison to the physically task time. This was observed when participants performed tasks under imagined loaded conditions (Cerritelli et al., 2000; Decety et al., 1989) and during actual performance on a beam walking task after having simulated it (Decety, 1991). In the latter case, the time to mentally complete the task also increased with the difficulty of the task (i.e., reducing the width of the beam). In contrast, actual movement duration was found to exceed imagined movement duration for uncommon hand orientations and uncomfortable kinesthetic sensations (Parsons, 1994) and for skill in speech production (Mackay, 1981). A number of explanations have been offered for the disparity between mental and actual durations. In tasks concerning carrying weights, Decety et al. (1989) and Jeannerod (1994) have suggested that during imagery conditions, individuals perceive extra force as an increase in duration. In tasks involving unfamiliar actions, Parsons (1994) has proposed that the imagery process is incapable of completely taking into account the characteristics of unfamiliar postures and that this may explain the generation of sketchy and rapid simulations for such tasks. In speech production tasks, Mackay $(1981,1982)$ suggested that reading a sentence mentally, as quickly as possible, was faster than saying it overtly because it did not involve full recruitment of the motor system. Linked to this idea, physically producing an action prior to starting imagery of the same action might promote greater additional kinesthetic awareness and, potentially, alter the timing of the image. Research findings in this area have been contradictory. Coello and Orliaguet (1992) showed that, for novice golf players, the duration of an imaged movement did not vary whether or not there were preliminary physical executions of the movement. In contrast, Decety (1991) found the opposite for undergraduate students who had to walk on wooden beams of different width. 
It seems that the time to execute a mental action is related to the time needed to actually perform the same action but that this relationship is complicated. When durations of actions are expressed as a function of the durations of imagined movements or vice-versa (Cerritelli et al., 2000; Decety et al., 1989; Mackay, 1981) a close correlation is seen. Chronometric studies have tended to compare actual and mental durations of entire actions. Simple motor skills such as locomotion tasks, visually-guided pointing tasks, arm and hand movements and graphic movements have been used. More recently, in the sport domain, Calmels and Fournier (2001), Le Her, Hertogh, and Garzaro (1997), Minvielle-Moncla, Ripoll, and Audiffren (2003), and Reed (2002) have considered more complex, whole body tasks. In these studies, the time to imagine a performance was quicker than that of the actual performance. They also reveal that the relationship between actual and simulated movement is modified by the complexity of the skill or the participants' expertise (e.g., Reed, 2002). Reed has suggested that task complexity has an effect on the imagery-action relationship; as rotational complexity increased, imaged times increased relative to the physical times. She also proposed that temporal discrepancies between imagined and actual behavior may be a consequence of schematic differences in skill representation since expertise modifies the cognitive organization of a skill (Karmiloff-Smith, 1990). In Reed's (2002) study, the divers did not possess the same level of expertise and their knowledge about how to perform dives may not have been similar, resulting in different imagery times. Intermediate divers took longer to develop dive elements for imagined performance in comparison to expert divers, for whom element assemblage was suggested to be automated. In contrast, novice divers had faster imagery times than intermediate divers because they possessed less fundamental technical knowledge concerning diving. 
Dividing an action into discrete temporal epochs allows examination of the duration of the different stages of an action under imagined and actual conditions. This provides the opportunity to appraise the time course of mental processing. It also allows consideration of the mechanisms involved as individuals perform an action under different conditions. More specifically, investigating whether different conditions of generating an action (i.e., actually or mentally) modify the temporal organization of the stages that constitute this action.

To our knowledge, this kind of temporal division of an action has only been considered in three studies: Calmels and Fournier, (2001); Minvielle-Moncla et al., (2003); and Reed, (2002). These studies showed that during imagery conditions, there was temporal disruption of the different stages of an action. Participants performed significantly faster in imagery than during the physical conditions. Unfortunately, in two studies of the studies, the visual perspective used in the imagery condition was not specified. This is important, because if, as Farrer and Frith (2002) have shown, changed visual perspective is associated with a different neural expression, it is possible that temporal components of a task are also modified.

To obtain a greater understanding of the temporal relationship between mental and actual representation activity, investigating the visual perspective characteristics of imagery that effect their functional equivalence may prove fruitful (see Holmes \& Collins, 2001 for a review). In the studies discussed above, and as reported by Ruby and Decety (2001) and Sirigu and Duhamel (2001), where imagery perspective has been specified, imagery was reported to be performed from an internal, first-person perspective (i.e., imaging the execution of a skill as if looking through one's own eyes). However, in the sport psychology literature, researchers have referred to imagery from two perspectives: a first-person and a third-person perspective (i.e., viewing movement from the perspective of an external observer) (see Hardy \& Callow, 1999; White \& Hardy, 1995). 
The two perspectives seem to be controlled by different processes (e.g., Farrer \& Frith, 2002). Brain areas activated during a first-person perspective, as revealed through positron emission tomography (PET), do not match those activated during a third-person perspective (Decety et al., 1994). The former has been proposed to "rely on motor-kinesthetic information processing" whereas the latter "rely more on visuospatial processing" (Decety, 1996, p.46) and do not preferentially use motor mechanisms (Sirigu \& Duhamel, 2001). Ruby and Decty (2001) have also shown that whilst imagery an action from a first and third-person perspective activated common brain areas (i.e., SMA, the precentral gyrus, the precuneus, and the occipito-tempoal junction) further specific activity was observed in the third-person perspective (right inferior parietal cortex and precuneus) and during a first-person perspective (left inferior parietal cortex and somatosensory areas). In support of the evidence for some perspective specificity, Fourkas, Avenanti, Urgesi, and Aglioti (2006) have provided evidence that imagery of a movement increased corticospinal excitability and that this excitability was greatest during a third-person perspective in comparison to a first-person perspective.

If neural correlates are associated with temporal patterning of behavior then these structural differences suggest that the timing of different imagery perspective may also be different. If the third-person perspective relies on more spatial processes (Decety, 1996; Sirigu \& Duhamel, 2001), mental simulation may be faster than actual execution because it does not seem to evoke motor processing (Mackay, 1981, 1982). Following a similar line of argument, imagined movements performed from a first-person perspective should have a temporal pattern closer to that of the physical movement because the motor representations employed are similar to those activated during physical execution of the action with the exception of motor output (Jeannerod, 1997). Whilst not directly linked to temporal patterning, the case for a first-person perspective has also been shown by Wang and Morgan (1992). Their study of visual perspective effects on imagined exercise demonstrated that 
ventilation and effort sense were higher when an internal imagery perspective was employed compared to an external imagery perspective. Despite some observed similarities between internal and external conditions in metabolic and cardiovascular responses, the authors concluded that internal imagery had the closest resemblance to actual exercise.

It was of interest, therefore, to examine the temporal functional equivalence for a complex task during imagery from an internal visual perspective (i.e., first-person perspective) and also from an external visual perspective (i.e., third-person perspective). Consideration of the temporal organization of a complex task under these conditions was proposed to reveal information relating to motor control processes and further increase understanding of the relationship between mental and actual behavior duration.

It was predicted that an internal visual perspective would show greater temporal functional equivalence with the physical condition compared to the external visual perspective for the full action. The external visual perspective was hypothesized to show significantly faster times than the internal perspective and the actual action times. No a priori hypotheses were offered concerning the temporal organization of the complex task under imagined and actual conditions, since there was insufficient literature to support informed predictions. Gymnastics routines offer diverse elements executed by the whole body around longitudinal, transversal and/or lateral axes. An exercise on the vault was chosen because of the ease with which routines can be broken down into clearly defined, recognized stages. Each stage is interpreted in the same way for each gymnast and so provides easily accessible epochs for comparison. In addition, using elite female athletes as participants offers a high level of ecological validity and population rarely seen in the psychology literature. 
Method

\section{Participants}

Seventeen female artistic gymnasts aged between 12 and 18 years (mean age $=14.5$, $\mathrm{SD}=1.63$ years) participated in the study. One participant was removed from the experiment since she did not meet the imagery requirements (see Procedure section). All the gymnasts competed at national level and comprised the entire junior French team. Each gymnast participated in at least 25 hours of physical training per week and had been supported by sport psychology training for at least three months. Separate written informed consent was obtained from the gymnasts and their parents.

\section{Experimental Task}

The study required the gymnasts to execute a Yurchenko vault. This involved rotating the whole body around both longitudinal and transversal axes. The vaulting exercise comprises a 25 meter-run-up to a springboard (Stage 1). The gymnast lands two-footed on the springboard to gain height and moves through the air towards the vault box (Stage 2). The hands are placed on the vault box before pushing off (Stage 3) to allow the gymnast to land on the mat (Stage 4) (see Figure 1.). The Yurchenko vault was chosen since it was considered as a complex routine because of the inclusion of a round off entry and a backward somersault only able to be performed by elite gymnasts. All the participants in this study had successfully completed a Yurchenko vault prior to the study and had included it in their performance repertoire in a major competition.

\section{Materials}

Pre-experimental questionnaires. In order to determine the participants' preferred imagery perspective, three methods were used: the French version (Fournier, Le Cren, \& Monnier, 1994) of the Vividness of Movement Imagery Questionnaire (VMIQ) (Isaac, Marks, \& Russell, 1986); verbalized reports from the gymnasts that related to the imagery perspective 
they employed in their training and competitive pre-vault preparation; and assessment from each gymnast's sport psychologist. The VMIQ 24-item questionnaire uses a 5-point Likerttype scale to measure the imagery vividness of a number of movements from two visual perspectives. First, when a movement is imaged from an external visual or third-person perspective (TPP), and second, when it is imaged from an internal visual or first-person perspective (FPP). Scores range from a low of 24 to a high of 120 for each perspective. A low rating (24-48) indicates low imagery vividness, whereas a high rating (96-120) indicates high imagery vividness (Goginsky, 1992). The VMIQ assessment of the preferred imagery perspective only monitors the quality of the image content in terms of its vividness. To reduce the emphasis placed just on vividness, gymnasts were also questioned about the imagery perspective they used during vault training sessions and in competition. Independent reports by the gymnast's sport psychologist were also collected. The participants were instructed to employ the perspective that scored highest on the VMIQ and concurred with their own reports and those of their sport psychologist.

Post-experimental questionnaires. This session comprised two parts. First, as recommended by Goginsky and Collins (1996), full manipulation checks and debriefs followed the experimental sessions through self-report questionnaires and discussion with the gymnasts. Full manipulation checks and debriefs were used to ensure that the participants were not estimating the time or counting during the period when they were imaging.

Clarification was also made to ensure that the perspective used by the participants during the experimental session was the same as the perspective identified by the VMIQ. Debriefs also confirmed that the gymnasts were not switching from one perspective to another one within the mental simulation and that they had followed the instructions for the content of imagery. Second, information concerning the gymnasts' imagery process was also assessed. This included the ease of image control, the imagery vividness, the use of other imagery 
modalities (e.g., auditory, kinesthetic, olfactory), and any emotion associated with the imagery process. The following questions were asked: Using the 5-point scale, was it easy or difficult to generate mental images?; how vivid were your images?; what did you see as you mentally simulated your vault routine?; do you think you simulated mentally your whole vault, and each of its four stages, at the same rate as in reality, or was it quicker or slower?; as you mentally simulated your vault routine, did you feel any sensations in your muscles?; did you experience any emotional states?; did you speak to yourself during imagery and, if so, what did you say?

\section{Procedure}

The procedure involved three stages: a pre-experimental questionnaire session; an experimental session; and a post-experimental questionnaire session. This approach was based upon a modified version of those employed by Decety and coworkers (e.g., Decety \& Jeannerod, 1996; Decety et al., 1989; Decety \& Michel, 1989).

Pre-experimental questionnaires session. The VMIQ was completed by each gymnast one week before the beginning of the experimental session. Eleven gymnasts were identified as FPP users. They had a mean of $91.4(\mathrm{SD}=15.99)$ for the FPP and a mean of $76.6(\mathrm{SD}=$ 18.64) for the TPP. A Wilcoxon test revealed a significant difference between the two perspectives $(Z=2.80, p<.006)$. Six gymnasts were classified as TPP users. They obtained a mean of $96.67(\mathrm{SD}=12.82)$ for the TPP and a mean of $85.33(\mathrm{SD}=17.90)$ for the FPP. Again, a significant difference was found between the two perspectives $(Z=2.02, p<.05)$.

There was full agreement across all assessment methods. The preferential perspective for each gymnast matched that identified through the VMIQ and was consistent with the reports of the corresponding gymnast. One participant, with no dominant VMIQ perspective, indicated switching between imagery perspectives when mentally rehearsing her vault. She was removed from the study. 
Experimental session. A between-subject design was employed in the present study.

The gymnasts were free to warm-up before starting the experimental session using their normal routines. During this period of time, the experimental team did not control the way participants prepared themselves to execute the actual vault and whether imagery was used. The experimentation began after the gymnasts indicated that they were ready.

The gymnasts were asked to imagine performing the vault task in their preferred imagery perspective. Imagery was performed in a standing position to address the postural force concerns for temporal functional equivalence raised by Holmes and Collins (2001, 2002). Before imaging performing each vault exercise the following instructions were provided to the gymnast, "I will ask you to imagine performing your vault with the understanding that you are going to execute your vault in reality after having imagined it. You should perform your imagery from your usual [internal/external] perspective.”

To consider the impact of timing congruence on the components of an action the vault was divided into four stages:

Stage 1: The Run Phase. From the start of the run-up to the gymnast's feet hitting the springboard;

Stage 2: The First Flight Phase. From the end of Stage 1 to hands hitting the vault; Stage 3: The Arm Support Phase. From the end of Stage 2 to the hands take-off from the vault;

Stage 4: The Second Flight Phase. From the end of Stage 3 to the feet landing on the mat.

The four stages of the Yurchenko vault were defined in this way because they were familiar and meaningful to all the gymnasts and since they matched the typical learning stages of this particular vault. 
A finger tapping procedure was employed to allow the gymnasts to identify each stage of the vault during the imagery process. Gymnasts were instructed to tap their fingers on their thigh as they reached each stage transition and to make the onset of the tapping coincide with the beginning of each stage of the imagined vault. Five taps were performed whilst they imagined their vault and the four stages were identified for each participant. The motor command to tap the leg could be seen as adding time to the mental stage. However, we would suggest that the time to tap was perceived not to add extra time to the time required to imagine the movement since participants decided consciously to prepare their finger tap before actually doing it. This argument is in line with Libet (1985) who has shown that when individuals executed freely voluntary acts (e.g., flexion of the wrist at any time they chose), they became aware of their intention to move about $200 \mathrm{~ms}$ before they actually moved. A conscious anticipation seems to be present that would not significantly increase movement times in the imagery conditions. Gymnasts were given five practice attempts to habituate to the signaling system and reinforce that tapping at the start of each phase.

The second element of the experimental session required the gymnasts to physically execute their vaults. The gymnasts performed an imaged execution of their vault followed by a physical execution of the skill. This protocol maintained the reality of the training and competition behavior. Indeed, Calmels, d'Arripe-Longueville, Fournier, and Soulard (2003) have shown that just prior to the execution of their competitive routine, elite gymnasts regularly simulate it mentally. Three trials were performed in each of the two conditions (i.e., imagined trial 1 followed by actual trial 1, imagined trial 2 followed by actual trial 2 , imagined trial 3 followed by actual trial 3). The gymnasts were filmed under both mental and actual conditions using a $25 \mathrm{~Hz}$ digital camcorder (Panasonic DS 15, mini DV). This procedure allowed for the collection of total and stage times for the vault. The duration of each stage was read from the frame timer of the camcorder. 
Post-experimental questionnaire session. Full manipulation checks and debriefs were employed after the experimental session. The imagery process was also monitored for each gymnast.

\section{Results}

\section{Statistical Analysis}

ANOVAs were computed for the full Yurchenko vault time and for the separate times for the four stages of the vault. For both ANOVAs, trial number was used as a factor in the design, since mental durations could change across the three trials (see Decety, 1991). For each ANOVA, the homogeneity of variance (homoscedasticity) was checked using the Levene's test. Post-hoc comparisons were calculated using Tukey's HSD test.

All the variances showed homogeneity except trial 1 stage 3 under the physical condition. Therefore, we used a more rigorous alpha level to correct the violation of homogeneity (Tabachnick \& Fidell, 2001).

Full Yurchenko vault. A 2 × 3 × 2 (Perspective $\mathrm{x}$ Trial $\mathrm{x}$ Condition) ANOVA with repeated measures was computed for the two within-subjects factors (trial and condition). No interaction and no main effect was found for perspectives, for trials, or for conditions for the full vault (see Table 1). The duration of the full vault exercise was consistent across the three trials and in both perspectives, the time to imagine the full vault was not significantly different to the time required to physically perform it (see Table 2, Figure 2).

Four stages of the Yurchenko vault. A 2 x 4 x 3 x 2 (Perspective $\mathrm{x}$ Stage $\mathrm{x}$ Trial $\mathrm{x}$ Condition) ANOVA with repeated measures was computed for the three within-subjects factors (stage, trial, and condition). Only the significant effect(s) or interaction(s) have been reported in this sub-section. Significant and non significant results have been displayed in Table 3. 
ANOVA revealed a significant main effect for the stage factor, $\mathrm{F}(3,42)=434.8731, p$ $<.000001$ (see Table 3). Tukey's HSD post-hoc tests showed that irrespective of perspective, trial, and condition, duration of stage $1(3.569 \mathrm{sec})$ was greater than the duration of stages 2 $(0.630 \mathrm{sec})(p<.0002), 3(0.511 \mathrm{sec})(p<.0002)$, and $4(0.960 \mathrm{sec})(p<.0002)$. Durations of stages 2 and 3 were also less than the duration of stage $4(p<.007$, for stage $2 ; p<.0003$, for stage 3).

ANOVA revealed a significant stage-trial interaction, $\mathrm{F}(6,84)=2.7672, p<.02$ (see Table 3). Regardless of perspective and condition, Tukey's HSD post-hoc tests indicated that trial durations did not change across each stage except for stage 1. Trial 1 duration $(3.504 \mathrm{sec})$ was faster than trial 3 duration $(3.621 \mathrm{sec})(\mathrm{p}<.03)$.

ANOVA displayed a significant stage-condition interaction, $\mathrm{F}(3,42)=125.9179, p<$ .000001 (see Table 3). Tukey's HSD post-hoc tests showed that participants using both visual perspectives mentally simulated stage 1 (run phase) at a faster rate $(\mathrm{p}<.001)$ and stages 2 and 3 (first flight phase and arm support phase) at a slower rate $(p<.0004$, for stage $2 ; p<.0003$, for stage 3) than they actually performed these stages during actual execution (see Figure 2 and Table 2).

\section{Post-experiment Questionnaire}

Participants' answers to the questionnaire established that they imagined performing the task from the agreed perspective. Answers also confirmed that the gymnasts did not omit any stages of the vault exercise. Participants also reported having experienced ease in generating images and having formed clear and vivid images. During imagery, six participants (three FPP and three TPP) expressed having experienced anxiety, three (one FPP and two TPP) reported having felt kinesthetic sensations during the second and third stages of the vault exercise, four (four FPP) declared having covertly verbalized (technical advice), and 
1 four (two FPP and two TPP) mentioned having heard the sound of their feet when they ran,

2 hit the springboard and landed on the mat, and of their hands as they hit the vault.

Discussion

In this study, we aimed to investigate the temporal functional equivalence between physical performance of a gymnastic vault and imagery of the same task from an internal visual perspective and also from an external visual perspective. We also aimed to consider the temporal organization of a complex task under imagined and actual execution from an internal and external imagery perspective. The discussion is organized into three sections. The first considers the chronometric comparison of actual and imaged full vault. The second section discusses the chronometric comparison of actual and imaged vault stages and the third considers the strengths and limitations of the study.

\section{Chronometric Comparison of Actual and Imaged Full Vault}

The findings of the present study showed that in an internal perspective imagery situation, the time to image the full vault was not significantly different to the time required to physically perform it. The finding provides support for previous behavioral studies (Decety \& Michel, 1989; Papaxanthis et al., 2002) that have shown that overt motor production and motor imagery (i.e., imagery from a FPP) share similar brain mechanisms and activate similar planning programs (Decety \& Michel, 1989). It is possible that mental simulation and execution of an action may be exposed to the same environmental and physiological constraints (Papaxanthis et al., 2002) and governed by the same temporal rules (Maruff et al., 1999). The absence of differences in mental and actual durations of the vault exercise could also be due to the sensory and proprioceptive inputs related to movement performance. This 'stored', or regenerated information was presumably used during the image generation for mental simulation (Decety, 1991; Kosslyn, 1994). It is, therefore, tempting to support the claims of other researchers (Decety, 1991; Lewis \& Miall, 2003) for the existence of an 
1 internal clock for mental and actual executions. The finding that motor imagery and physical

execution of a skill may share a similar temporal driver should not be completely surprising given the volume of research showing the activation of common brain areas for these two processes (Grèzes \& Decety, 2001).

The novelty of the present study was that imagery was also performed from an external visual perspective. It was predicted that mental simulation of the full vault would be faster than actual execution since the external visual perspective should involve less motor processing as suggested by Mackay $(1981 ; 1982)$. This was not the case. The time to imagine the full vault from a third-person perspective was not significantly different to the time required to physically perform it. We suggest that this finding may be explained by research that has shown that the cortical motor system was active during both overt movement and external imagery of a rotation task (e.g., Ganis, Keenan, Kosslyn, \& Pascual-Leone, 2000; Kosslyn, Digirolamo, Thompson, \& Alpert, 1998). Imaging the full vault from an external visual perspective required the gymnast to simulate mental rotations. Therefore, we suggest that motor, in addition to visual, mechanisms may be active during the external visual imagery condition and that this may explain the equality between actual and imagined actions.

For skilled performers, internal and external visual imagery displayed the same temporal characteristics. This suggests that imagery conducted from a third-person perspective may contain sufficient propositional information for these individuals to access the representation in the same way as an internal perspective (Holmes \& Collins, 2001, 2002).

\section{Chronometric Comparison of Actual and Imaged Vault Stages}

Trial was included as a factor in the design since Decety (1991) has showed that there is the potential for temporal inconsistency across actual and imagined trials as a result of feedback. This was not the case in this study and probably reflects the skill level of the participants. In only one case (trial 1 duration was faster than trial 3 duration for the first stage 
of the vault irrespective of perspective and condition) was there a difference. The condition factor (mental and actual) and the perspective factor (internal and external) were indistinguishable since they were averaged in the post-hoc comparisons. Only the stage factor and trial factor could be discriminated.

The data also revealed that the temporal aspects of the vault components were not consistent across imagery and actual conditions. Participants in both visual perspective conditions imaged stage 1 (run phase) at a significantly faster rate than the physical condition, stages 2 and 3 (first flight phase and arm support phase) at a significantly slower rate as the physical condition and stage 4 (second flight phase) at the same speed as that which they actually performed.

Stage 1 was the approach run to the springboard and its function was to provide horizontal acceleration for the gymnast in preparation for the acrobatic movements. The temporal discrepancy in stage 1 between the imagery and physical conditions for the participants for both perspectives could be explained by Loomis, Da Silva, Fujita, and Fukusima's (1992) foreshortening effect. In this regard, Stevens (2005) has recently suggested that individuals minimize the distance in the imagined condition in the same way distances in the depth plane are perceptually foreshortened. Therefore, this visual distortion reduces the movement mental duration.

The duration of the imagined stages 2 and 3 (first flight phase and arm support phase) was longer than the duration of the actual stages. These findings are consistent with those of Orliaguet and Coello (1998) who argue for the absence of a temporal equivalence between mental and actual movements where actual durations are around 250ms. They have suggested that imagined and actual movements of this time scale do not share the same processing systems. For fast movement, no possibility of 'closed-loop' regulation of the movement is available to individuals as they actually execute it. During the mental simulation of 
movements with short duration, participants focus more on the unfolding of the action that might have evoked sensorial modes related to the motor act (Orliaguet \& Coello, 1998). This explanation is supported by the reports of the participants in the present study who declared having heard their feet hit the springboard and their hands hit the vault, and having felt kinesthetic sensation during stages 2 and 3 of their mental simulation. These reports of conscious percepts during imagery are in contrast to the actual movement where no such reports are made since the activity is performed in a less conscious state. These different levels of processing may account directly for the temporal discrepancy between the imagined and physical conditions during these stages.

A further explanation can be proposed to explain the longer mental duration of these stages. Decety et al. (1989) and Jeannerod (1994) have shown that participants perceived an increase in force as an increase in mental movement duration. This proposal supports the gymnasts' reports. They explained that stages 2 and 3 required more effort and force than the other stages because "you have to hit the springboard strongly and to push your arms to perform successfully" (Gymnast X). The absence of these afferent forces during both imagery conditions may have been perceived as additional time (Jeannerod, 1997).

The different results observed for the vault stages may also be explained by the relationship between actual and mental duration which can be modified by the length of the motor sequence. In the present study, the first stage, where imagined movement time was faster than actual movement time, was also longer in duration than the other stages.

Conversely, stages 2 and 3, for which imagery times were slower than the actual times, were very short in (actual) duration. Few studies have examined this point in the literature and opinions vary as to its explanation. Minvielle-Moncla et al. (2003) have argued against the length of the motor sequence having an influence on the difference between mental and actual duration. In contrast, Le Her et al. (1997) showed that the time it took to image surfing on a 
wave interacted with the actual duration of the wave; the longer the actual duration of a wave, the shorter the mental duration of surfing on this wave. The relationship between actual and simulated movement is clearly not simple. Reed (2002) has also shown that the relationship can be altered by the participants' expertise and by the complexity of the skill. She showed that, as skill complexity increases, imagery durations become longer and that, unlike novices or experts, imagery durations for intermediate divers were slower than those of actual durations. The extent that movement complexity and/or duration influenced imagery times in the current study cannot be fully discussed and certainly warrants further investigation.

In a practical sense, it is also possible that stages 2 and 3 were extended in the imagery conditions as a direct result of the emphasis placed on these elements by coaches at this level of performance. The coach's reinforcement of these skills may direct attention to them during imagery at the expense of the run up and landing. Therefore, whilst these aspects of the vault may have shown temporal functional equivalence, the gymnasts' tacit knowledge of the component importance results in a relatively greater amount of time being spent on it during imagery.

\section{Strengths and Limitations of the Study}

This study investigated a series of complex motor skills performed by expert athletes. These participants are not numerous and the findings may only be applicable to similarly skilled groups. A within-subject comparison of imagery would have been a more effective design, but to maintain ecological validity this was not possible. The gymnasts were unable to employ the alternative visual perspective; in fact, they refused to mentally simulate their vault exercise from their non-dominant perspective knowing that the aim was to perform the action afterwards. A significantly modified pre-performance routine was considered unethical if changing their imagery routines increased the risk of them being hurt. We also recognize that 
1 the results could be linked equally to imagery perspective or imagery ability with the current design. Future research should examine this issue further.

Despite these limitations, the study presents important findings. First, it has investigated the functional equivalence concept of a complex, well-learnt motor skill performed by elite athletes in an ecologically-valid setting. Second, dividing the action into stages has supplied a more refined appraisal of the temporal organization of a complex action not previously considered. Third, examining the temporal functional equivalence during imagery from an external visual perspective should promote greater use of this perspective for experienced performers as its temporal aspects were found to be the same as those of the internal perspective. Finally, the debrief interviews highlighted that there may be a number of additional imagery characteristics that may have had an influence on imagined time. These include concurrent kinesthesis which has been shown to influence image time. However, the reports of kinesthesis were consistent across visual perspective and therefore remain to be examined more fully in future studies.

\section{Conclusion}

At the simplest level, the study would seem to provide partial support for functional equivalence considered through a timing paradigm. The findings revealed that the duration of an imagined motor task was not significantly different from the time required to actually perform it irrespective of the visual perspective employed. However, when the motor task was considered more fully in its component stages, correspondence between imagined and actual times was lost. Three of the four stages of the task exhibited absolute temporal discrepancies between the imagery and physical conditions. These results cannot be discussed in the context of any previous research because, to our knowledge, no research has fully addressed this relationship. These results suggest the cautious interpretation of previous research in this area since the use of total time as a measure in a multi-component task may not be appropriate and 
1 may conceal some important features of the task. Further understanding the disparity between

2 imagined and actual times and exploring the multifarious influences on imagined time

3 certainly warrant further investigation.

5

6

7 
2 The authors are grateful to the elite gymnasts who participated in the study. 
2 Calmels, C., d'Arripe-Longueville, F., Fournier, J.F., \& Soulard, A. (2003). Competitive

\section{References} strategies among elite female gymnasts: An exploration of the relative influence of psychological skills training and natural learning experiences. International Journal of Sport and Exercise Psychology, 1, 327-352.

Calmels, C., \& Fournier, J. (2001). Duration of physical and mental execution of gymnastic routines. The Sport Psychologist, 15, 142-150.

Cerritelli, B., Maruff, P., Wilson P., \& Currie, J. (2000). The effect of an external load on the force and timing components of mentally represented actions. Behavioural Brain Research, 108, 91-96.

Coello, Y., \& Orliaguet, J-P. (1992). Exécution réelle ou imaginée d'un mouvement de putting au golf : études des interférences temporelles [Real or imagined execution of a putting movement in golf: Study of temporal interferences]. In M. Laurent, J.F. Marini, R. Pfister, \& P. Therme (Eds.) Recherches en APS 3 (pp. 133-142). Paris : Actio / Université Aix-Marseille II.

Crammond, D.J. (1997). Motor imagery: Never in your wildest dream. Trends in Neuroscience, 20, 54-57.

Decety, J. (1991). Motor information may be important for updating the cognitive processes involved in mental imagery of movement. European Bulletin of Cognitive Psychology, 11, 415-426.

Decety, J. (1996). Review article. The neurophysiological basis of motor imagery. Behavioural Brain Research, 77, 45-52.

Decety, J., \& Grèzes, J. (1999). Neural mechanisms subserving the perception of human actions. Trends in Cognitive Science, 3, 172-178. 
1 Decety, J., \& Jeannerod, M. (1996). Mentally simulated movements in virtual reality: Does Fitts's law hold in motor imagery. Behavioral Brain Research, 72, 127-134.

Decety, J, Jeannerod, M., \& Prablanc, C. (1989). The timing of mentally represented actions. Behavioural Brain Research, 34, 35-42.

Decety, J., \& Michel, F. (1989). Comparative analysis of actual and mental movement times in two graphic tasks. Brain and Cognition, 11, 87-97.

Decety, J., Perani, D., Jeannerod, M., Bettinardi, V., Tadary, B., Mazziotta, J.C., Woods, R., \& Fazio, F. (1994). Mapping motor representations with positron emission tomography. Nature, 371, 600-602.

Farrer, C., \& Frith, C. D. (2002). Experiencing oneself vs another person as being the cause of an action: the neural correlates of the experience of agency. Neuroimage, 15, 596-603.

Fourkas, A.D., Avenanti, A., Urgesi, C., \& Aglioti, S.M. (2006). Corticospinal facilitation during first and third person imagery. Experimental Brain Research, 168, 143-151.

Fournier, J., Le Cren, F., \& Monnier, E. (1994, September). Validation et adaptation en langue française du questionnaire de clarté de l'image du mouvement. [Validation and adaptation in French of the Vividness of Movement Imagery Questionnaire]. Paper presented at the International Conference of the French Sport Psychology Society (SFPS), Poitiers, France.

Ganis, G., Keenan, J.P., Kosslyn, S.M., \& Pascual-Leone, A. (2000). Transcranial magnetic stimulation of primary motor cortex affects mental rotation. Cerebral Cortex, 10(2), 175180.

Goginsky, A. M. (1992). Imagery/physical practice schedules in the enhancement of dart throwing performance. Unpublished doctoral thesis, University of Pennsylvania, USA.

Goginsky, A.M., \& Collins, D. (1996). Research design and mental practice. Journal of Sports Sciences, 14, 381-392. 
1 Grèzes, J., \& Decety, J. (2001). Functional anatomy of execution, mental simulation, observation, and verb generation of actions : A meta-analysis. Human Brain Mapping, $12,1-19$.

Grèzes, J., Fonlupt, P., \& Decety, J. (2000). Equivalence fonctionnelle: mythe cognitif ou réalité neurologique? [Functional equivalence: Cognitive myth or neurological reality?] Psychologie Française, 4, 319-332.

Guillot, A., \& Collet, C. (2005). Duration of mentally simulated movement: A review. Journal of Motor Behavior, 37(1), 10-20.

Hardy, L., \& Callow, N. (1999). Efficacy of external and internal visual imagery perspectives for enhancement of performance on tasks in which form is important. Journal of Sport and Exercise Psychology, 21, 95-112.

Holmes, P.S., \& Collins, D.J. (2001). The PETTLEP approach to motor imagery: A functional equivalence model for sport psychologists. Journal of Applied Sport Psychology, 13, 60-83.

Holmes, P. S., \& Collins, D. J. (2002). The problem of motor imagery: A functional equivalence solution. In I. Cockerill (Ed.) Solutions in sport psychology (pp.120-140). London: Thomson Learning.

Isaac, A., Marks, D.F., \& Russell, D.G. (1986). An instrument for assessing imagery of movement: The vividness of movement imagery questionnaire (VMIQ). Journal of Mental Imagery, 10, 23-30.

Jeannerod, M. (1994). The representing brain: Neural correlates of motor intention and imagery. Behavioral and Brain Sciences, 17, 187-245.

Jeannerod, M. (1997). The cognitive neuroscience of action. Oxford, UK: Blackwell Publisher Ltd. 
1 Jeannerod, M. (1999). The $25^{\text {th }}$ Bartlett lecture. To act or not to act: Perspectives on the representation of actions. The Quarterly Journal of Experimental Psychology, 52A, 1-29.

Karmiloff-Smith, A. (1990). Constraints on representational change: Evidence from children's drawing. Cognition, 34, 57-83.

Kosslyn, S.M. (1994). Image and brain. Cambridge, MA: MIT Press.

Kosslyn, S.M., Digirolamo, G.J., Thompson, W.L., Alpert, N.M. (1998). Mental rotation of objects versus hands: Neural mechanisms revealed by positron emission tomography. Psychophysiology, 35, 151-161.

Le Her, M., Hertogh, C., \& Garzaro, E. (1997, November). Etude des caractéristiques temporelles de l'image mentale du mouvement chez les surfeurs. [Temporal characteristics of mental imagery in surfers]. Paper presented at the 7th International Conference of Researchers in Physical and Sport Activities (ACAPS), Marseille, France.

Lewis, P.A., \& Miall, R.C. (2003). Overview: An image of neural human timing. In W.H. Meck (Ed.), Functional and neural mechanisms of interval timing (pp. 515-532). London: CRC Press.

Libet, B. (1985). Unconscious cerebral initiative and the role of conscious will in voluntary action. The Behavioral and Brain Sciences, 8, 529-566.

Loomis, J.M., Da Silva, J.A., Fujita, N., \& Fukusima, S.S. (1992). Visual space perception and visually directed action. Journal of Experimental Psychology: Human Perception and Performance, 18, 906-921.

Mackay, D.G. (1981). The problem of rehearsal or mental practice. Journal of Motor Behavior, 13, 274-285.

Mackay, D.G. (1982). The problems of flexibility, fluency, and speed-accuracy trade-off in skilled behavior. Psychological Review, 89, 483-506. 
1 Maruff, P., Wilson, P.H., De Fazio, J., Cerritelli, B., Hedt, A., \& Currie, J. (1999). Asymmetries between dominant and non-dominant hands in real and imaged motor task performance. Neuropsychologia, 37, 379-384.

Minvielle-Moncla, J., Ripoll, H., \& Audiffren, M. (2003). The effect of expertise on spatial and temporal representations of a choreographed dance solo. International Journal of Sport and Exercise Psychology, 1(4), 372-389.

Munzert, J. (2002). Temporal accuracy of mentally simulated transport movements. Perceptual and Motor Skills, 94, 307-318.

Orliaguet, J.P., \& Coello, Y. (1998). Differences between actual and imagined putting movements in golf: A chronometric analysis. International Journal of Sport Psychology, 29, 157-169.

Papaxanthis, C., Pozzo, T., Kasprinski, R., Berthoz, A. (2003). Comparison of actual and imagined execution of whole-body movements after a long exposure to microgravity. Neuroscience Letters, 339, 41-44.

Papaxanthis, C., Scieppati, M., Gentili, R., \& Pozzo, T. (2002). Imagined and actual arm movements have similar durations when performed under different conditions of direction and mass. Experimental Brain Research, 143, 447-452.

Parsons, L.M. (1994). Temporal and kinematic properties of motor behavior reflected in mentally simulated action. Journal of Experimental Psychology: Human Perception and Performance, 20, 709-730.

Reed, C.L. (2002). Chronometric comparisons of imagery to action: Visualizing versus physically performing springboard dives. Memory and Cognition, 30(8), 1169-1178.

Ruby, P., \& Decety, J. (2001). Effect of subjective perspective taking during simulation of action: A PET investigation of agency. Nature Neuroscience, 4, 546-550. 
1 Sirigu, A., \& Duhamel, J.R. (2001). Motor and visual imagery as two complementary but neurally dissociable mental processes. Journal of Cognitive Neuroscience, 13(7), 910-919.

Stevens, J.A. (2005). Interference effects demonstrate distinct roles for visual and motor imagery during the mental representation of human action. Cognition, 95, 329-350.

Tabachnick, B.G., \& Fidell, L.S. (2001). Using multivariate statistics. London: Allyn and Bacon.

Wang, Y., \& Morgan, W. P. (1992). The effect of imagery perspectives on the psychophysiological responses to imagined exercise. Behavioural Brain Research, 52, 167-174.

White, A., \& Hardy, L. (1995). Use of different imagery perspectives on the learning and performance of different motor skills. British Journal of Psychology, 86, 169-180. 


\section{$1 \quad$ Table 1}

2 Summary of the $2 \times 3 \times 2$ (Perspective $x$ Trial $x$ Condition) ANOVA

3

\begin{tabular}{lcc}
\hline & $\mathrm{F}$ & $\mathrm{p}$ \\
\hline Perspective & 1.475 & 0.24 \\
\hline Trial & 0.417 & 0.66 \\
\hline Condition & 2.631 & 0.13 \\
\hline Perspective x Trial & 1.960 & 0.16 \\
\hline Perspective x Condition & 0.092 & 0.77 \\
\hline Trial x Condition & 0.201 & 0.82 \\
\hline Perspective x Trial x Condition & 1.214 & 0.31 \\
\hline
\end{tabular}

4 
Table 2

Means and Standard Deviations of Imagined and Actual Durations (in seconds)

\begin{tabular}{|c|c|c|c|c|c|c|c|c|c|c|}
\hline & \multicolumn{2}{|c|}{ Full vault } & \multicolumn{2}{|c|}{ Stage 1} & \multicolumn{2}{|c|}{ Stage 2} & \multicolumn{2}{|c|}{ Stage 3} & \multicolumn{2}{|c|}{ Stage 4} \\
\hline & Mean & SD & Mean & SD & Mean & SD & Mean & SD & Mean & SD \\
\hline \multicolumn{11}{|c|}{ Participants imaging from a first-person perspective } \\
\hline Imagined trial 1 & 4.98 & 1.92 & 2.21 & 0.71 & 0.89 & 0.49 & 0.78 & 0.52 & 1.11 & 0.52 \\
\hline Imagined trial 2 & 4.78 & 2.06 & 2.10 & 0.77 & 0.92 & 0.51 & 0.75 & 0.57 & 1.01 & 0.51 \\
\hline Imagined trial 3 & 4.96 & 2.07 & 2.24 & 0.83 & 0.89 & 0.50 & 0.78 & 0.58 & 1.05 & 0.50 \\
\hline Imagined trials & 4.91 & 1.95 & 2.18 & 0.75 & 0.90 & 0.49 & 0.77 & 0.54 & 1.05 & 0.49 \\
\hline Actual trial 1 & 5.80 & 0.46 & 4.43 & 0.46 & 0.31 & 0.03 & 0.22 & 0.05 & 0.84 & 0.09 \\
\hline Actual trial 2 & 5.81 & 0.39 & 4.46 & 0.43 & 0.32 & 0.02 & 0.19 & 0.03 & 0.85 & 0.09 \\
\hline Actual trial 3 & 5.92 & 0.36 & 4.54 & 0.38 & 0.32 & 0.04 & 0.20 & 0.03 & 0.86 & 0.07 \\
\hline Actual trials & 5.84 & 0.40 & 4.48 & 0.41 & 0.31 & 0.03 & 0.20 & 0.04 & 0.85 & 0.08 \\
\hline
\end{tabular}

Participants imaging from a third-person perspective

\begin{tabular}{ccccccccccc} 
Imagined trial 1 & 5.50 & 1.60 & 2.49 & 1.09 & 1.04 & 0.45 & 0.89 & 0.46 & 1.08 & 0.49 \\
\hline Imagined trial 2 & 5.84 & 1.45 & 2.82 & 1.20 & 1.04 & 0.46 & 0.86 & 0.51 & 1.12 & 0.51 \\
& & & & & & & & & & \\
\hline Imagined trial 3 & 5.60 & 1.67 & 2.77 & 1.04 & 0.85 & 0.37 & 0.85 & 0.45 & 1.13 & 0.44 \\
& & & & & & & & & & \\
\hline Imagined trials & 5.65 & 1.49 & 2.69 & 1.05 & 0.98 & 0.42 & 0.87 & 0.45 & 1.11 & 0.45 \\
& & & & & & & & & & \\
\hline Imagined trial 1 & 6.24 & 0.48 & 4.89 & 0.43 & 0.33 & 0.04 & 0.20 & 0.01 & 0.82 & 0.12 \\
\hline Actual trial 2 & 6.30 & 0.43 & 4.95 & 0.42 & 0.34 & 0.04 & 0.21 & 0.02 & 0.80 & 0.10 \\
& & & & & & & & & & \\
\hline Actual trial 3 & 6.32 & 0.36 & 4.93 & 0.36 & 0.33 & 0.02 & 0.20 & 0.02 & 0.87 & 0.06 \\
\hline Actual trials & 6.29 & 0.40 & 4.92 & 0.38 & 0.33 & 0.03 & 0.20 & 0.02 & 0.83 & 0.09
\end{tabular}


Table 3

2 Summary of the $2 \times 4 \times 3 \times 2$ (Perspective $x$ Stage $x$ Trial $x$ Condition) ANOVA

3

\begin{tabular}{|c|c|c|}
\hline & $\mathrm{F}$ & $\mathrm{p}$ \\
\hline Perspective & 1.475 & 0.24 \\
\hline Stage & 434.873 & $* * *$ \\
\hline Trial & 0.416 & 0.66 \\
\hline Condition & 2.630 & 0.13 \\
\hline Perspective $\mathrm{x}$ Stage & 2.512 & 0.07 \\
\hline Perspective $\mathrm{x}$ Trial & 1.960 & 0.16 \\
\hline Stage x Trial & 2.767 & $*$ \\
\hline Perspective $\mathrm{x}$ Condition & 0.092 & 0.77 \\
\hline Stage $\mathrm{x}$ Condition & 125.918 & $* * *$ \\
\hline Trial x Condition & 0.200 & 0.82 \\
\hline Perspective $\mathrm{x}$ Stage $\mathrm{x}$ Trial & 1.848 & 0.10 \\
\hline Perspective $\mathrm{x}$ Stage $\mathrm{x}$ Condition & 0.004 & 0.99 \\
\hline Perspective $\mathrm{x}$ Trial $\mathrm{x}$ Condition & 1.213 & 0.31 \\
\hline Stage $\mathrm{x}$ Trial $\mathrm{x}$ Condition & 0.750 & 0.61 \\
\hline Perspective $\mathrm{x}$ Stage $\mathrm{x}$ Trial $\mathrm{x}$ Condition & 1.534 & 0.18 \\
\hline
\end{tabular}

4

$* * * \mathrm{p}<.000001, * \mathrm{p}<02$ 
1

Figure Captions

3

4

5 6

7

Figure 1. The Yurchenko vault and its four stages four stages irrespective of visual perspective

Figure 2. Mean times (sec) for the 16 gymnasts for the imagined and physical actions and the 


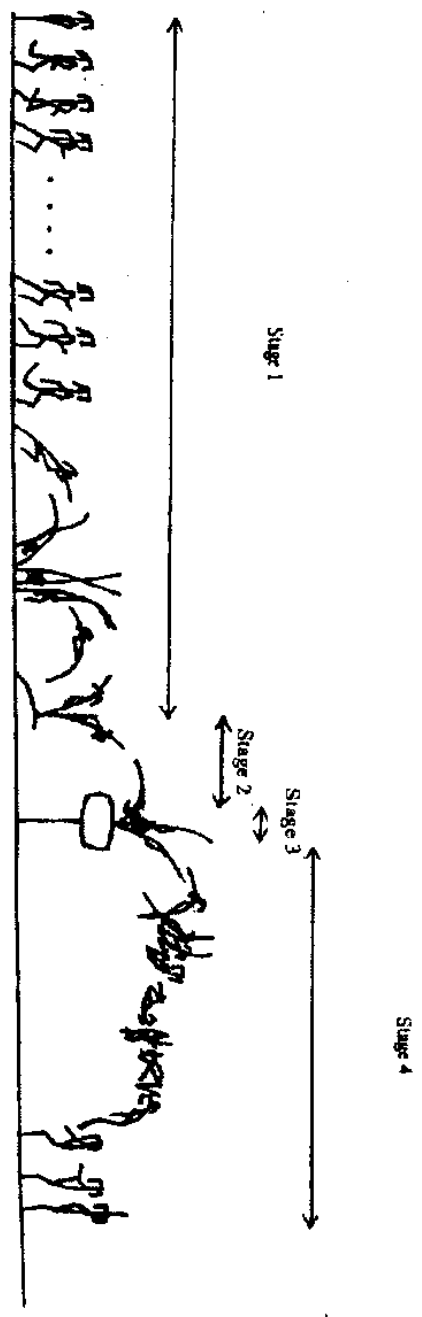




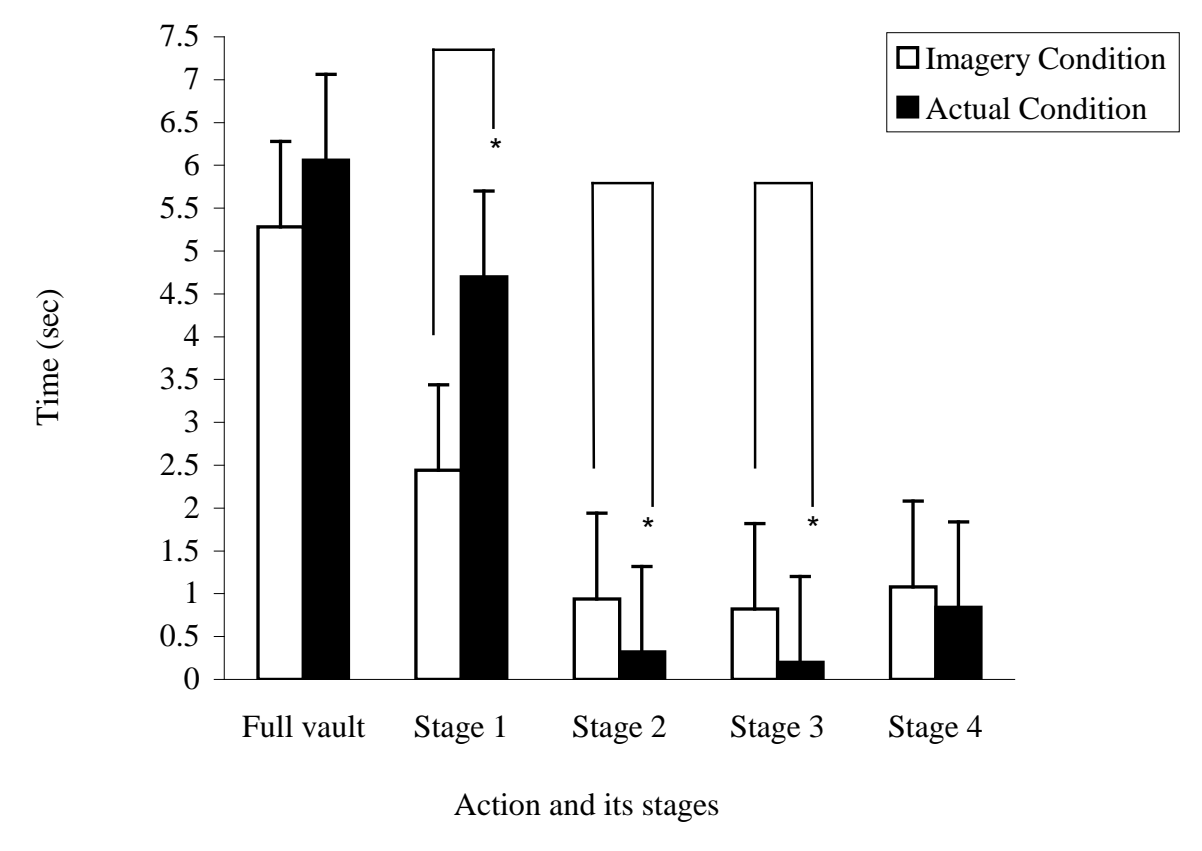

